\title{
THE INTERACTION: BUSINESS- EDUCATION- INVESTMENT FOR DEVELOPMENT
}

\author{
Venelin Terziev ${ }^{1}$, Marusya Lyubcheva ${ }^{2}$, Denis Solovev ${ }^{3}$ \\ ${ }^{1}$ Full Member of the Russian Academy of Natural History, Professor, Eng,
} D.Sc. (National Security), D.Sc. (Economics), D.Sc. (Social Activities), Ph.D., Russian Academy of Natural History, Moscow, Russia, Vasil Levski National Military University, Veliko Tarnovo, Bulgaria University of Rousse, Rousse, Bulgaria, terziev@skmat.com

${ }^{2}$ Associate Professor, Ph.D., University "Prof. d-r Assen Zlatarov" - Bourgas, Bulgaria, milyubcheff@gmail.com

${ }^{3}$ Associate Professor, Ph.D., Far Eastern Federal University (FEFU), Vladivostok, Russian Federation, solovev.db@dvfu.ru

\begin{abstract}
The change of the management business model has been widely discussed in the recent years - the one of the country as well as that of single structures, sectors and organizations. This is a serious intervention for each of these levels as far as it requires a strategic transformation to be made.

Universities are among the institutions, for which the business model transformation (or its establishing) becomes more and more urgent.

The report examines possible options for developing the relationship between the education system with the economy.
\end{abstract}

Keywords: education, development, business model, investment, business environment.

\section{INTRODUCTION}

Modern technological development implies an intensive transfer of knowledge and skills. The channels of this transfer are different, but there is one major one, and it is the one which starts with education. The almost eternal topic for the connection between education and business environment/economics has had its different dimensions during different periods of the development of the two systems, but has always contained one essence - knowledge and skills acquired in education, which transfer to the jobs in economic subjects. This transfer is almost direct at the lower level of technological development, because the school basis is sufficient to satisfy the needs of the respective technology, equipment, machine. Such a "direct" transfer is difficult to achieve in the 21st century. This is so due to the accumulated differences in the dynamics of development of the two systems. The educational system is lagging behind the economical one and is gradually losing its ability to satisfy the requirements which are being placed on it. Such a tendency is characteristic of all educational systems of the modern development of society. Some have quickly created effective mechanisms for overcoming this inequality. This process continues to accumulate deficits in Bulgaria, regardless of the attempts to transfer external models of interaction, which, in our opinion, are impossible to be automatically approbated and in practice cannot realize the missions of their carriers. This creates a particular discomfort in the development of the educational system, by limiting the development of 
the social technologies, the social ones in particular. Discussing this issue, it is important to ask the right questions (specific and accurate ones) in order for the right answers to be found as well - the affected groups (which we can clearly and accurately determine and distinguish), the possible models (applicable in the dynamically changing environment), a toolkit (contributing to the development of social technologies). An important point is to monitor this interaction in order to ensure a corresponding analysis and decisions to be made, related to its effectiveness, efficiency, sustainability, and flexibility.

The importance of the controlling mechanism and the ability to accurately account for defects in methodology, technology or in the process as a whole, would allow for quick and accurate corrective actions. In the period of active transformations in the last thirty years, the evaluation mechanisms are mostly followup, and if there are such that are throughout the whole impact process, then the corrective actions are with low effectiveness or are after the end of the monitoring. It is not particularly acceptable to make decisions for corrective actions after the conclusion of a rather long period of time (a few years). Part of the specialists in this field are trying to explain that the effect of the introduction of new models and technologies is manifested at a later stage. This statement is also not devoid of logic, but the negative impact of an incorrect assessment of the current condition will increase and even repeatedly multiply the final negative result.

Unfortunately, the results of the models, technologies, programs, etc introduced so far, brings the situation to a rather critical level, as the two systems - the educational and economic one - move away and do not find the points of contact that are fundamental. It is correct to point out from a scientific point of view that the educational system is perhaps part of the economic system and that in this particular case we should consider it as the system of the national economy.

\section{THE INTERACTION: BUSINESS- EDUCATION- INVESTMENT FOR DEVELOPMENT}

There are several keywords that determine our attitude towards the interaction education - business environment in the conditions of "knowledge-based economy" - dynamics, high technological effectiveness, key skills, digitalization, artificial intelligence, innovations, investments.

Of substantial importance is the change that is currently taking place in the labour market, linked to the need to have multiple skills to solve the multitude of problems with which a job is connected with. The time of narrow specialists is passing, and this must be clear both to education as well as to the business environment. However, the two systems have a different understanding and a different interpretation of the situation, and this creates the deficits we are witnessing.

Undoubtedly, the national labour market is a dynamic system which has its own characteristics. Even within the scales of the different regions of Bulgaria, it has different and considerably distinctive characteristics. This is especially typical in areas where the unemployment rate is much higher than the one for the country. It turns out that having a degree of higher education is not a sufficient condition to ensure the proper employment of a particular group of specialists due to the lack of need for such in this area. Obviously, the market mechanism that demand will determine supply, does not fulfill its function. This is not an isolated phenomenon and is observed in many of the crisis areas of the country. The lack of the planning element from this management process places insurmountable obstacles to the individual in these areas. It is possible that the bearers of this workforce have good competences - skills and experience, and cannot realize a successful result in the search of a job. The low mobility of the workforce in these areas also causes a negative impact. This problem cannot be examined unilaterally because it includes in itself various elements that can be difficult to overcome. Sometimes this is related to the Bulgarian folk psychology. Infrastructure, transport links, social adaptation in the new locality, etc can be included in this group of reasons.

Education and the economy are two independent areas of social relations, and they can be situated in different positions relative to each other. The conservative model of development puts the two systems in relative equilibrium. Education is perceived as a given, almost an appendage, without being given any exclusivity whatsoever. It is being relied on "ready cadres" that are simply redistributed from one system to another. In this model, the level of education and the level of technological effectiveness have a relative correspondence, or at least the impression of such a status quo is maintained - i.e. whatever is being studied, it exists in practice in the economic subjects, due to which the transfer is direct without there being a need for additional education and training. The overall system is balanced. This may be called a model of sufficiency.

The dynamic model leads the economy to a priority position due to the higher level of technological development. Education is lagging behind in terms of the practical part, though it retains its level in terms of the theoretical educational preparation. Transfer from one of the systems to another is no longer direct, it can 
be defined as indirect, due to the need for adaptation or additional education and training. The level of correspondence is low, the overall system of accumulation of added value is imbalanced.

The "relationships" between education and business can evolve under different scenarios - systems are independent of each other; education determines the direction of development; business determines the direction of development; both systems develop according to an adaptive mechanism. In different periods and under different socio-political systems, these scenarios or combinations between them occur in different options.

The 21 st century is characterized by high technological effectiveness and high dynamics. We are talking about Industry 4.0., that is, about the fourth industrial revolution. After mechanization (Industry 1.0), mass production (Industry 2.0) and automation (Industry 3.0), which can be referred to the model of sufficiency, digitalization is now becoming an integral part of production. Industry 4.0 has the potential to create extraordinary opportunities for growth and competitive advantages. Prognoses indicate that enterprises will be able to increase their productivity by about $30 \%$ if they use Industry 4.0 . At the same time, education does not have its "Education 4.0", despite the advent of computer technology and the Internet, both at school and at university. However, this advent is only as an auxiliary and not a leading tool. Remaining at level 2.0 or 3.0 , education is not able to directly transfer its educational product to the industry. In this case, the deficit is present and it is by no means imperceptible. This categorically requires to be analyzed all possible options for the realization of the scenarios of the interaction education - business environment, all the positives and negatives to be taken into account, in order to find that one which would satisfy the development of society.

The interaction business environment - education is realized in the structure of the educational system and in the context of the corresponding socio-economic system, but this is not the only factor that influences it. The conditionality of this consideration boils down to discussing the interaction of vocational education and business, i.e. the pair which provides realization through professions / higher education is also included in vocational education, providing professional realization in respective professional fields /.

The traditional understanding of the relationships between education and the economy / business is defined by the status quo "education educates - the economy consumes". This understanding is characteristic of different economies - predominantly planned public or private ones. Naturally with characteristic nuances. The new understanding includes a new paradigm - continuous education / lifelong learning /, which can be realized outside the educational system, incl. on the terrain of the economy. This understanding also relates to different types of economies (fig. 1).

\section{ROLES IN THE DEVELOPMENT}

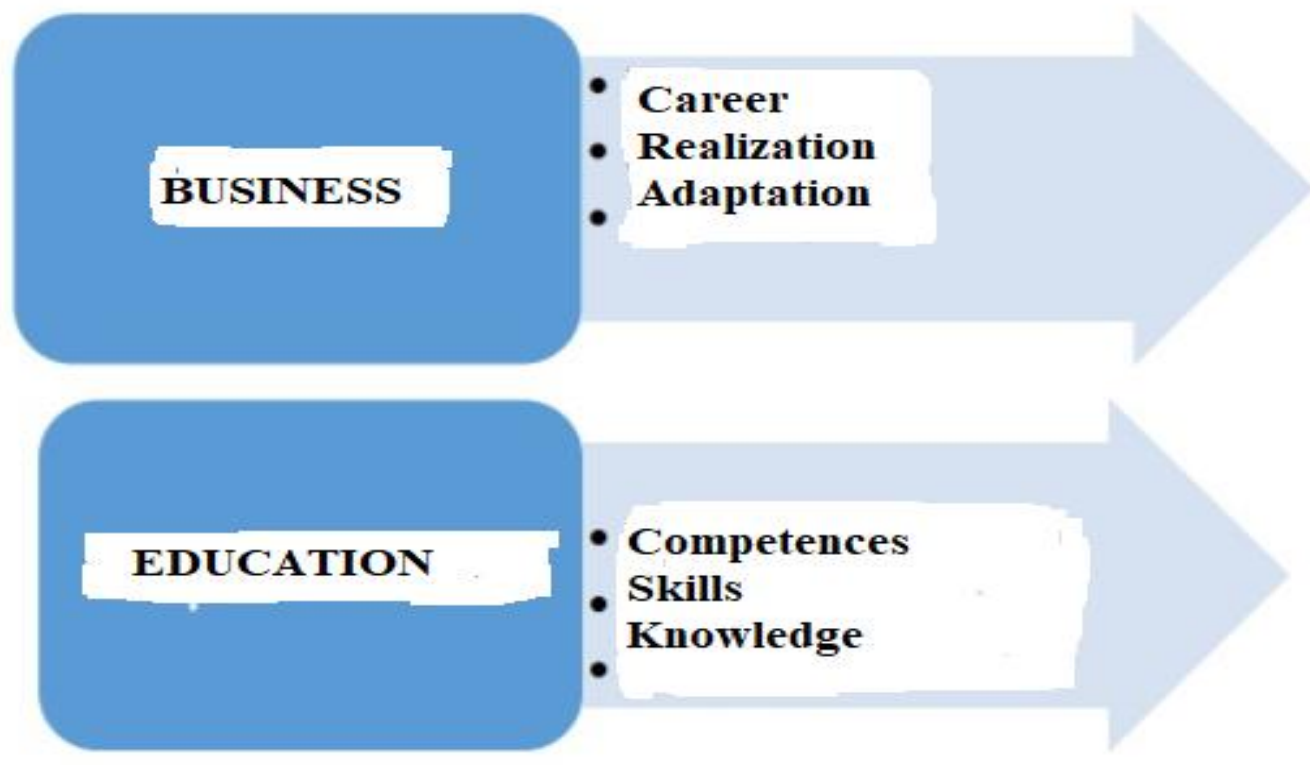

Fig. 1. Roles in the development.

Option "Full Regulation". In this model, the process of entry and exit from the vocational education system is completely controlled. It implies strict and synchronized planning, so that the concurrence of the exit from the educational system and the entry to the economic part, is close to $100 \%$. Planning is a critical zone in 
this model - it must be carried out by the economic part by providing information about jobs according to vocational directions, educational degree and qualifications, and the respective administrative educational structures should determine the required admission for entry. This means, in addition to "usual" planning, the methods of forecasting research are also to be applied, which will support the long-term decisions for the labour market. It should be understood here that the educational system produces that which can be realized in the economic part. In this model, $100 \%$ realization of graduates of a certain degree of the educational system (vocational education) is accomplished. The model can be implemented in any socio-economic system. From the point of view of freedom of choice, mobility, the democratism of the functioning of systems, this option is very restrictive. From the point of view of securing employment and reducing the unemployment rate, it has its positive elements, because even with the differences between education and the economy in terms of quality of preparation, insufficient knowledge, lack of qualifications, etc., the full regulation is implemented. Such an option may be applicable in regions with critical employment rates, severe and undesirable social processes, or after periods of disasters. This option may be similar to the linear structure of an organization in which each action is set and controlled with a clear result.

Option "Market Mechanism". Both systems are free in planning, in the case of such. / Many experts consider that, in a market economy, planning is an unnecessary process. In this context of reasoning, the Model implies a free determination of the entry to education and does not regulate synchronization with the entry to the economic part. Two important parameters come into view here - the educational market and the labour market, which interact to a certain extent but redundancies in different areas of professional directions appear, and "fashionable" professional directions emerge as well, which satisfy temporary deficits in one or another economic area. The educational market can be regulated through the appropriate state mechanisms by using the "capacity" criterion of the educational structures. The disproportions between the educational market and the labour market, i.e. between supply and demand, however, cause unemployment and a decrease in employment, or employment that needs additional training (without which it cannot be carried out). The lack of job vacancies for certain groups of professions can lead to discouragement for young specialists and provoke a number of reactions, including leaving the country. The surplus of specialists in other areas also acts restrictively on the social system and demotivating to the individual. This model is strongly liberal. Experts define it as "neoliberal" in the context of the common development policies. Based on the unification of the systems, the globalization of processes and ensuring the functioning of the single educational and single economic area (EU level). This option is usually realized in periods of change of socio-economic models of societies (societies in transition) and are elements of crisis factors for the economy.

Studies in the 2011-2018 period in different regions of the country show mutual dissatisfaction between the two systems. Education is developing by its own logic, regardless of the state regulation which is being implemented. The business is dissatisfied with the lack of cadres in certain areas and with the level of preparation of young specialists. Young specialists are dissatisfied with the quality of jobs and the lack of realization.

Option "Adaptation". This option can be established as an adequate collective image of all the others. It imposes a continuity in the improvement of the educational system by changing the curricula and programmes, which it can bear, and several synchronizing steps which are taken by the economic system, namely - organizing adaptive training for young specialists; internship period in the last years of studying; mixed teaching teams from among education and business representatives. This model requires an organization that needs sufficient freedom of action, initiative, innovation, two-way investments. An element of this option is the so called dual system. To realize it, an active working economy is required and a good environment for all forms of business - small, medium, large, so that results can be achieved in different directions and the economy does not develop unilaterally. This option has the potential to develop synergies because it can bring together the positive elements of both systems.

Option "Congruence". In theory, another option is possible, called "Congruence". This option is an antipode of the market one. It is rather difficult to implement unless there is a clear national policy, i.e. with clear synchronization, with continuous and accurate forecasting of the needs of the economic system in quantity (number) and quality (set of specialists), with a continuous change of the educational system to meet the requirements of the economy and to create mechanisms for transfer of knowledge and skills between both systems. Consumption prognoses must be accurate and the supply by the educational system as a response should be fully feasible. An important requirement for its realization is to have a dynamic model of development of the two systems - the educational and the economy, under the conditionality of the emergence of new or the disappearance of old professions and objectively anticipating the movement of the economy. In the presence of a relatively small labour market, this option is difficult to realize because it imposes high dynamics on the educational market, uncharacteristic of the conservative nature of the 
educational system, even with serious efforts in this direction.

The real mechanism of interaction is never unambiguous and one-sided - there is always a mix of different elements - conjunctural, political, as a result of the influence of the external environment. Very often this degree of influence is so strong that the internal environment cannot adapt, but is "subordinated" to the main influencing factors. This mechanism depends to a certain extent on the legislative norm, which often changes and causes transformations and reforms that are implemented without serious analyses, reliable impact assessment and risks. In the presence of such analyses of the condition of this interaction, they are sporadic, done according to different methodologies, by using a different toolkit, which makes the conclusions from them also ambiguous and ultimately incomparable. Even due to the fact that changes in the environment are dynamic enough and the formulation of a sustainable research toolkit are dependent on the situation and the respondents' willingness to participate in the studies.

The research conducted in the period between 2011 and 2018 outlines several groups of problems that need to be taken into account in the building up of a modern concept for the interaction education - business environment, which will correspond to the main principles and priorities of the concept Industry 4.0.

The study categorically indicates that economic subjects prefer the interaction with education to develop under the 'adaptive' scenario. Insofar as this expose is merely analytical in nature, without seeking specific examples and substantiating the theses of the authors, which are the result of our many years of efforts in this direction (Bogdanova, Terziev, 2019; Terziev, 2019a).

\section{CONCLUSION}

The social processes in the period of study do not imply full regulation of the interaction - the development of the economy according to market mechanisms implied the possibility of the interaction education - business under one of the other options - market or adaptive mechanism / as it became clear above, the congruence mechanism is almost theoretical/.The chances for implementing policies and strategies in this direction implies focusing the efforts and expertise of scientists, researchers, and of course the participants in these processes. Defining the same, or more precisely defining them in what direction, time range and territorial scope of action, is especially important (regardless of the relatively not big territory of the country). This type of social processes is especially difficult to analyze, monitor, predict, and manage. The indicators and criteria for their evaluation are complex, difficult to define, and mathematically difficult to describe. Our experience has shown that social technologies are far too advanced from scientific point of view, but difficult to adapt and transfer to another environment. The management of social processes, which undoubtedly include the elements of educational systems, economic systems, etc. are complex not only in their nature but also in their essence. This requires making a great deal of effort in this direction to achieve or to make the right and adequate development decisions in this direction (Georgiev, 2019b; Petrov, Georgiev, 2019c, Terziev, 2019a; Bogdanov, 2016-a; Bogdanov, 2019d).

\section{REFERENCE LIST}

Bogdanova, M., Terziev, V. (2019). Akademicheskiy kapitalizm i novaya biznes modely universitetov. // Mezhdunarodnayy nauchnayy zhurnal, Innovatsionnaya nauka, „Aeterna“, Ufa, 9, 2019, s. 32-39, ISSN 2410-6070 (Богданова, М., Терзиев, В. Академический капитализм и новая бизнес модель университетов. // Международный научный журнал, Инновационная наука, „Аэтерна“, Уфа, 9, 2019 , с. 32-39, ISSN 2410-6070).

Terziev, Venelin. (2019a). The development of education in Bulgaria. // Proceedings of SOCIOINT 2019-6th International Conference on Education, Social Sciences and Humanities 24-26 June 2019- Istanbul, Turkey, International Organization Center of Academic Research, Istanbul, Turkey, 2019, pp. 263-266, ISBN: 978-605-82433-6-1.

Georgiev, M. (2019b). Improvement of the forming of the military professional qualities during the educational process. // 21 st International scientific conference: The teacher of the future, Budva, Montenegro, (07-09.06.2019), Institute of knowledge management - Skopje, Macedonia, 31, 2019, 6, pp. 1945-1950, ISSN 1857-923X (for e-version), ISSN 2545 - 4439 (for printed version).

Petrov, N., Georgiev, M. (2019c). Assessing of the military professional competencies. // Proceedings of SOCIOINT 2019- 6th International Conference on Education, Social Scienc-es and Humanities 24-26 June 2019- Istanbul, Turkey, International Organization Center of Academic Research, Istanbul, Turkey, 2019, pp. 462-472, ISBN: 978-605-82433-6-1.

Bogdanov, Plamen. (2016). Osnovi na ekspeditsionnite sposobnosti. // Voenen zhurnal, Voenna akademiya 
„Georgi Stoykov Rakovski“, Sofiya, br. 1, 2016, str. 68-74, ISSN 0861-7392. (Богданов, Пламен. Основи на експедиционните способности. // Военен журнал, Военна академия „Георги Стойков Раковски“, София, бр. 1, 2016, стр. 68-74, ISSN 0861-7392).

Bogdanov, Plamen. (2016a). Air power - Today and tomorrow. // Tenth international scientific conference: The power of knowledge 7-9.10.2016, Agia Triada, Greece, IKM - Skopje, 14, 2016, N 1, pp. 331-336, ISSN 1857-92.

Bogdanov, Plamen. (2019d). Perspectives and development of the the Bulgarian military - educational system. // Security of Central and Eastern Europe Countries 1st International Scientific Conference of Military Academies/Universities, WROCLAW, 20-22.03.2019, organized by General Tadeusz Kosciuszko Military University of Land Forces, Scientific Journal of the Military University of Land Forces, volume 50, no. 1 (187), 2019, p. 73-89, ISSN 2544-7122. 